Canadian Journal of Plant Science Revue canadienne de phytotechnie

\title{
A second set of XEGIP-encoding genes resides on chromosome 8 of potato and tomato.
}

\begin{tabular}{|r|l|}
\hline Journal: & Canadian Journal of Plant Science \\
\hline Manuscript ID & CJPS-2016-0306.R2 \\
\hline Manuscript Type: & Article \\
\hline Date Submitted by the Author: & $22-$ Mar-2017 \\
\hline Complete List of Authors: & $\begin{array}{l}\text { Jones, Richard; USDA-ARS North East Area, GIFVL } \\
\text { Perez, Frances; USDA-ARS North East Area, GIFVL }\end{array}$ \\
\hline Keywords: & $\begin{array}{l}\text { xyloglucan-specific endoglucanase, late blight, potato, glucanase inhibitor } \\
\text { protein, Phytophthora }\end{array}$ \\
\hline & \\
\hline
\end{tabular}

SCHOLARONE ${ }^{\text {IM }}$

Manuscripts 
A second set of XEGIP-encoding genes resides on chromosome 8 of potato and tomato.

Corresponding Author: Richard W. Jones

E-mail : Richard.jones@ars.usda.gov

Frances G. Perez

E-mail: frances.perez@ars.usda.gov

Genetic Improvement of Fruits and Vegetables Laboratory, USDA-ARS, B010A, 10300

Baltimore Ave., Beltsville, MD 20705 USA 


\begin{abstract}
Xyloglucan-specific endoglucanase inhibitor proteins (XEGIP) are present in a wide range of dicots, where they are believed to play a role in defense from pathogens. The XEGIPs are generally present as two or three copies, however, they are reported to be present as a cluster of ten copies in potato and tomato on chromosome 1 . We have now identified a second set of XEGIP encoding genes, where two inverted copies are present on chromosome 8 of potato (Solanum tuberosum). The same set exists, in the same order, on chromosome 8 of tomato (Solanum pennellii). Transcript expression analysis indicates that XEGIP10 is transcribed only in roots, while XEGIP11 transcripts were not detected under normal growth conditions.

Transformed potatoes (cvs. Bintje and Kennebec) overexpressing these genes did not show any changes in phenology. Foliar screening of transgenic lines for resistance to the late blight pathogen Phytophthora infestans did not demonstrate a large reduction in disease progression or pathogen sporulation.
\end{abstract}

Keywords: xyloglucan-specific endoglucanase, late blight, potato

\title{
Introduction
}

Plants produce a number of inhibitory proteins that interact with proteases, pectinases, pectin methylesterases, xylanases and endoglucanases ( Juge 2006, Pogorelko et al. 2013). Production increases during biotic stresses, such as pathogen attack, and during abiotic stress such as temperature extremes. Since the inhibitory proteins can interfere with pathogen enzymes, they 
are believed to play a role in host defenses. Closer study indicates that the inhibitory proteins can have a direct effect on the host, independent of any pathogen interactions (Alexandersson et al. 2011, Jones and Perez 2014) which may help explain their up-regulation by abiotic stress. One group of inhibitory proteins is the xyloglucanase-specific endoglucanase inhibitor proteins (XEGIPs) found in dicots. These proteins were first discovered due to their interaction with a fungal endoglucanase in Glycosyl Hydrolase family 12 (Qin et al. 2003). A parallel inhibitory protein TAX-1 exists in monocots, and inhibits GH11 xylanases (Igawa et al. 2004). The Xegips are present in a wide range of dicots, found as two or three copies in the genomes (Qin et al. 2003, Jones 2012). An exception in copy number exists for the xyloglucan-specific endoglucanase inhibitor protein encoding genes in potato and tomato. Extensive duplication occurred at a pre-speciation time period, resulting in ten copies of Xegip within a $90 \mathrm{kB}$ region of chromosome 1 from potato and tomato (Jones 2012). During our ongoing analysis of potato XEGIP-encoding genes we identified a second set of Xegip genes clustered on another potato chromosome. We report on the sequence, transcription and effects in plant transformant expression.

\section{Materials and methods.}

\section{Identification, cloning and expression of Xegips.}

Genome sequences deposited at NCBI GenBank were periodically scanned using tblastn and sequences from previously identified potato Xegips (Jones 2012). Two sequences were identified in GenBank which mapped to potato chromosome 8. Primers spanning the predicted coding regions were used to PCR amplify the gene sequences from potato (cv. Russet Norkotah). The PCR products were cloned (TOPO 2.1, Invitrogen) and sequenced commercially in both 
directions (Macrogen,USA). Sequences were analyzed for signal peptides using SignalP 4 (Petersen et al. 2011).

Comparisons were made between the sequences found in potato and similar sequences detected in the tomato genome, using Simple Synteny (Veltri et al. 2016) (http://www.dveltri.com/simplesynteny) with an e-value cutoff threshold of 10.

Transcriptional analysis was performed using total RNA extracts (Zymogen RNA kit) from leaves and from roots. A cDNA template was prepared using ProtoScript (New England Biolabs) and oligo dT in a 20 microliter reaction, according to the manufacturer's protocol. One microliter of cDNA was used in a 40 microliter PCR reaction containing GoTaq (Promega) and one of the following primer sets; X10 f (atgaaattatctcctatgtcaccetcc) and X10 r (ccattcctttaacattttgcctaa), X11 f(atgtctatcatgtccaatatttacacac) and X11 r (cgatttcagcaccagagtagaaagt), Actin $\mathrm{f}$ (atgcatatgttggcgatgaagctcaa) and Actin $\mathrm{r}$ (agaggacagcttgaatggcgacatac) . PCR reactions were run at $96 \mathrm{C}$ for two minutes, followed by 30 cycles of $53 \mathrm{C}$ for $15 \mathrm{sec}, 72 \mathrm{C}$ for $40 \mathrm{sec}$, and $96 \mathrm{C}$ for $30 \mathrm{sec}$, followed by a final cycle of $5 \mathrm{~min}$ at $72 \mathrm{C}$. Three microliters of each reaction was loaded into a $1 \%$ agarose gel and run at $100 \mathrm{~V}$ for 30 min. Exposure time was based on absence of saturated pixels under UV illumination. Samples were quantified using BioRad Quantity One software.

\section{Transformation and plant regeneration.}

The gene was PCR amplified with primers to the coding region plus the addition of 5' Xba1 and 3'Sac1 restriction sites for X11 or Xho1 and BamH1 for X10. Amplified product was TOPO cloned (Invitrogen), and plasmid isolated after transformation into E. coli. Plasmid was restricted and the insert was gel purified (Zymo Genetics) then ligated with Instant Sticky End Ligase 
(New England Biolabs) into an Xba1-Sac1 restricted, gel purified pBI121 or Xho1-BamH1 restricted, gel purified pGD binary vector. Ligated vector-insert combinations were transformed into E. coli, and plasmid isolated for further use. Agrobacterium tumefasciens cells (LBA4404, Life Technologies) were electroporated with each of the two constructs.

Leaf tissues from tissue culture grown plantlets of potato (cvs. Kennebec and Bintje) were transformed as previously described (Jones et al. 2004). Rooted regenerants were screened by PCR amplification using 35S promoter and nos terminator primers. Plants were grown in a greenhouse until maturity. The PCR products generated throughout the study were sequenced to confirm sequence integrity. Transcript levels of X10 and X11 in the foliage of transformed plants were tested using the procedures outlined previously for detection of X10 and X11 transcripts in control plants.

\section{Inoculations with Phytophthora infestans}

Leaflets were removed from the center of two month old greenhouse grown plants and spot inoculated with a sporangial suspension of Phytophthora infestans US 11 as previously described (Jones and Perez 2014). Inoculated leaflets (two sets) were maintained in covered plastic boxes and assessed for lesion size and sporulation six days after incubation at $18 \mathrm{C}$.

\section{Results}

\section{Identification, cloning and transcript analysis.}

Two new Xegip genes were identified and named following the known potato Xegips (X-0 to X9). Sequences were deposited in GenBank as X10 (KF769949) and X11 (KC960886). The two 
sequences were found on the NCBI whole genome shotgun sequence (wgs) submission AEWC01019573 originating from potato (Solanum tuberosum). Similar sequences were also found on a tomato (Solanum pennellii) genome sequence HG975447. In both cases the genome sequence was found on chromosome 8 . Comparison of the regions was made using the web based program Simple Synteny (Veltri et al. 2016). Genes were located within $6 \mathrm{kB}$ of each other and transcription would occur in opposite directions (Fig. 1). Comparisons based on amino acid alignment of the two secreted proteins indicated a similar overall pattern, however X10 lacked the second arginine that is generally required to bind to GH 12 enzymes (Fig. 2).

Transcript analysis revealed that X10 transcripts are abundant in potato roots of the two cultivars tested, but they are lacking in the foliage. Transcripts for X11 were not evident in roots or foliage (Fig. 3).

\section{Transformation and regeneration.}

Independent lines of overexpressing X10 and X11 were obtained and grown in the greenhouse to maturity. The transgenic X11 lines were readily generated in both Bintje and Kennebec, while the X10 lines were difficult to regenerate, resulting in only four transgenic Bintjes and one transgenic Kennebec. While the regeneration was poor for X10, there were no phenotypic differences in growth or tuber formation in mature plants for either cultivar tested for X10 or X11. Under normal greenhouse growth, transcripts of X10 and X11 are not produced in leaf tissue, thus it is not possible to compare transgene expression levels between transgenics and the control plants. However, all transgenic plants expressed transcripts of the corresponding transgene in the foliage, with a maximum of two-fold difference between the highest and lowest expressing transgenic. 


\section{Inoculation with Phytophthora infestans.}

Individual leaflets of greenhouse grown transformed plants did not show large differences in disease (lesion size) or sporulation. (Table 1). The effect of X10 was slightly greater than X11 in transformants, but at best they contribute to a slight reduction in lesion size and sporulation.

\section{Discussion}

The identification of two new XEGIP-encoding genes in potato expands the number of Xegips to twelve. The high number of Xegips is similar to the high number of GH12 xyloglucan-specific endoglucanase encoding genes reported in P. infestans (Costanzo et al. 2006), suggesting a pattern of co-evolution. Based upon blastn analysis, the X10 and X11 genes are most closely related to X1, which is located at the 5' end of the Xegip gene cluster on chromosome 1. A phylogenetic tree comparing all the previously reported Xegip genes from potato has been published (Jones 2012). It can only be speculated if one cluster is the progenitor of the other through a translocation.

An interesting aspect of the new Xegips is the transcript presence. We did not find X11 transcripts in control plants under greenhouse conditions, while X10 transcripts were abundant in roots and absent in foliage. Expression of XEGIPs can be very tissue-specific, an example being NEC4, found in the nectar of tobacco (Navqi et al. 2005). There are no apparent ESTs for X11 in GenBank, while there is EST confirmation for X10. It has been noted that the late blight resistant potato cultivar Sarpo Mira relies on the presence of roots to exhibit the full defense response (Orlowska et al. 2012). It would be of interest to determine if specific XEGIP proteins could be translocated to other parts of the plant. Regions of the legume genome harboring Xegips have been associated with resistance to the root attacking nematode Pratylenchus (Oldach et al. 2014), 
thus there may be specific pests and pathogens that are differentially affected by individual XEGIPs. In tobacco, one XEGIP was studied and shown to have an effect on susceptibility to a bacterial pathogen, but no effect on two fungal pathogens (Xie et al. 2008).

Introducing the production of two new XEGIPs to the foliage of potato through transformation allowed for functional testing of these XEGIPs in their ability to interfere with $P$. infestans infections. Neither XEGIP is normally produced in potato foliage, however transcripts were readily detected from cDNA of the transgenics. On an individual basis, neither XEGIP resulted in sufficient reduction in lesion size to be considered exclusively as a disease control measure. There was a general reduction in lesion size and sporulation that could be beneficial if added along with other defense genes. The limited effectiveness may be due to the complexities introduced by the large number of GH12 enzymes produced by $P$. infestans, or that interference with GH 12 is insufficient to limit Phytophthora. Transformant expression of a TAX-1 xylanase inhibitor in wheat grain spikes (Moscetti et al. 2013) delayed Fusarium head blight, providing one of the few examples where an inhibitor similar to XEGIP was effective. In this case there is a less complex situation with the limited number of GH 11 xylanases being produced by the pathogen.

The amino acid sequence suggests that X10 may not be a good inhibitor of GH 12 enzymes, although it should be noted that xyloglucan-specific endoglucanase activity exists in GH 5 and GH 74 families also. There are two arginines required for binding to the inner pocket of GH 12 (Yoshizawa et al. 2012), and the second one is absent in X10. This does not mean that it could not interact with other enzymes. 
XEGIPs can take on many different functions in addition to neutralizing GH 12 enzymatic activites. Studies in tobacco nectar have shown that binding of XEGIP with GH 12 initiates secondary effects that have a direct impact on pathogen success (Harper et al. 2010). In hops and apple ( Habrylo et al. 2013, Bai et al. 2015), only some of the XEGIPs interact directly with GH 12, while a role for direct activity on the host is suggested for the other XEGIPs. This was demonstrated with $\mathrm{X}-0$ in potato, where overexpression led to drastically altered plant phenotypes (Jones and Perez 2014). Altered phenotypes were not observed when overexpressing the XEGIPs in this study, demonstrating that each XEGIP can differ in function.

The number of XEGIPs in other dicots may need to be re-evaluated, given the large number that still remain mis-annotated. While some are identified as similar to aspartic proteases, many are identified as basic 7S globulins. These proteins have a similar structure, but lack inhibitory activity (Scarafoni et al. 2010, Yoshizawa et al. 2011). The true globulins form tetramers at proper $\mathrm{pH}$ and have other functions in the plant. Within the globulin family, unique characteristics have been discovered that could allow them to be inhibitory. While normally processed, the lack of processing found in a yeast expression system lead to the discovery of activity against GH11 xylanase (Scarafoni et al. 2016).

\section{Literature cited.}

Alexandersson E., Becker J., Jacobson D., Nguema-Ona E., Steyn C., Denby K.J. and Vivier M.A. 2011. Constitutive expression of a grapevine polygalacturonase-inhibiting protein affects gene expression and cell wall properties in uninfected tobacco. BMC Res. Notes 4:493. 
Bai S., Dong C., Zhu J., Zhang Y. and Dai H. 2015. Identification of a xyloglucan-specific endo(1-4)-beta-d-glucanase inhibitor protein from apple (Malus $\times$ domestica Borkh.) as a potential defense gene against Botryosphaeria dothidea, Plant Sci. 231:11-19.

Costanzo S., Ospina-Giraldo M.D., Deahl K., Baker C. and Jones R.W. 2006. Gene duplication event in family 12 glycosyl hydrolase from Phytophthora spp. Fungal Genet. Biol. 43:707-714.

Habrylo O., Forster A., Jeltsch J.M. and Phalip V. 2013. The characterisation of xyloglucanase inhibitors from Humulus lupulus. Phytochemistry 90:70-77.

Harper A., Stalnaker S., Wells L., Darvill A., Thornburg R. and York W. 2010. Interaction of nectarin IV with a fungal protein triggers a microbial surveillance and defense mechanism in nectar. Phytochemistry 71:1963-1969.

Igawa T., Ochiai-Fukuda T., Takahashi-Ando N., Ohsato S., Shibata T., Yamaguchi I. and Kimura M. 2004. New TAXI-type xylanase inhibitor genes are inducible by pathogens and wounding in hexaploid wheat. Plant Cell Physiol. 45:1347-1360.

Jones R.W. 2012. Multiple copies of genes encoding XEGIPs are harbored in an 85-kB region of the potato genome. Plant Mol. Biol. Rep. 30:1040-46.

Jones R.W. and Perez F.G. 2014. Constitutive expression of a XEGIP in potato results in phenotypic changes suggesting endogenous inhibition of cell wall growth. Potato Res. 57:133144.

Jones R.W., Ospina-Giraldo M.D. and Clemente T. 2004. Prosystemin-antimicrobial peptide fusion reduces tomato late blight lesion expansion. Mol. Breeding 14:83-89. 
Juge N. 2006. Plant protein inhibitors of cell wall degrading enzymes. Trends Plant Sci. 11:359367.

Moscetti I., Tundo S., Janni M., Sella L., Gazzetti K., Tauzin A., Giardina T., Masci S., Favaron F. and D’Ovidio R. 2013. Constitutive expression of the xylanase inhibitor TAXI-III delays Fusarium head blight symptoms in durum wheat transgenic plants. Mol. Plant Path. Interac. 26:1464-1472.

Naqvi S., Harper A., Carter C., Ren G., Guirgis A., York W. and Thornburg R.W. 2005. Nectarin IV, a potent endoglucanase inhibitor secreted into the nectar of ornamental tobacco plants. Isolation, cloning, and characterization. Plant Physiol. 139:1389-1400.

Oldach, K., Peck D., Nair R.M., Sokolova M., Harris J., Bogacki P. and Ballard R. 2014. Genetic analysis of tolerance to the root lesion nematode Pratylenchus neglectus in the legume Medicago littoralis. BMC Plant Biology 14:100.

Orlowska E., Basile A., Kandzia I., Llorente B., Kirk H.G. and Cvitanich C. 2012. Revealing the importance of meristems and roots for the development of hypersensitive responses and full foliar resistance to Phytophthora infestans in the resistant potato cultivar Sarpo Mira. J. Exp. Bot. 63:4765-4779.

Petersen TN., Brunak S., von Heijne G. and Nielsen H. 2011. SignalP 4.0: discriminating signal peptides from transmembrane regions. Nature Methods, 8:785-786.

Pogorelko G., Lionetti V., Bellincampi D. and Zabotina O. 2013. Cell wall integrity. Plant Signal. Behav. 8:9, e25435. 
Qin Q., Bergmann C., Rose J., Saladie M., Kolli V., Albersheim P., Darvill A. and York W. 2003. Characterization of a tomato protein that inhibits a xyloglucan-specific endoglucanase. Plant J. 34:327-338.

Scarafoni A., Ronchi A. and Duranti M. 2010. Gamma-conglutin, the Lupinus albus XEGIP-like protein, whose expression is elicited by chitosan, lacks of the typical inhibitory activity against GH12 endoglucanases. Phytochemistry 71:142-148.

Scarafoni A., Consonni A., Pessina S., Balzaretti S., Capraro j., Galanti E. and Duranti M. 2016. Structural basis of the lack of endo-glucanase inhibitory activity of Lupinus albus gammaconglutin. Plant Physiol. Biochem. 99:79-85.

Veltri, D., Malapi-Wight, M. and Crouch J.A. 2016. SimpleSynteny: a web-based tool for visualization of microsynteny across multiple species. Nucleic Acids Res. 44(W1):W41-W45.

Xie W., Hao L., Goodwin P.H. 2008. Role of a xyloglucan-specific endo- $\beta$-1,4-glucanase inhibitor in the interactions of Nicotiana benthamiana with Colletotrichum destructivum, $C$. orbiculare or Pseudomonas syringae pv. tabaci. Mol. Plant Pathol 9:191-202

Yoshizawa T., Shimizu T., Yamabe M., Taichi M., Nishiuchi Y., Shichijo N., Unzai S., Hirano H., Sato M. and Hashimoto H. 2011. Crystal structure of basic 7S globulin, a xyloglucan-specific endo-beta-1,4-glucanase inhibitor protein-like protein from soybean lacking inhibitory activity against endo-beta-glucanase. FEBS J. 278:1944-1954.

Yoshizawa T., Shimizu T., Hirano H., Sato M. and Hashimoto H. 2012. Structural basis for inhibition of xyloglucan-specific endo-1,4-glucanase (XEG) by XEG-Protein Inhibitor. J. Biol. Chem. 287:18710-18716. 


\section{Figure Captions}

Figure 1. Comparison of locations for X10 (KF769949) and X11 (KC960886) on a region of chromosome 8 of potato (Solanum tuberosum) and tomato (Solanum pennellii). Diagram generated by SimpleSynteny shows the conservation in transcriptional direction and general distance between the two copies.

Figure 2. Amino acid alignment by ClustalW comparing secreted proteins from X10 (AHG54973), X11 (AGT17598), X0 (AAP84703) and X1 (ADU58603). Arrows indicate conserved arginines that bind with GH 12.

Figure 3. Transcript analysis of control plants. Transcripts are only present for X10 and only in root samples. Lane 1, Bintje leaf X10, lane 2 Bintje root X10, lane 3 Kennebec leaf X10, lane 4 Kennebec root X10, lane 5 Bintje leaf X11, lane 6 Bintje root X11, lane 7 Kennebec leaf X11, lane 8 Kennebec root X11, lane 9 Bintje leaf actin, lane 10 Bintje root actin, lane 11 Kennebec leaf actin, lane 12 Kennebec root actin. 


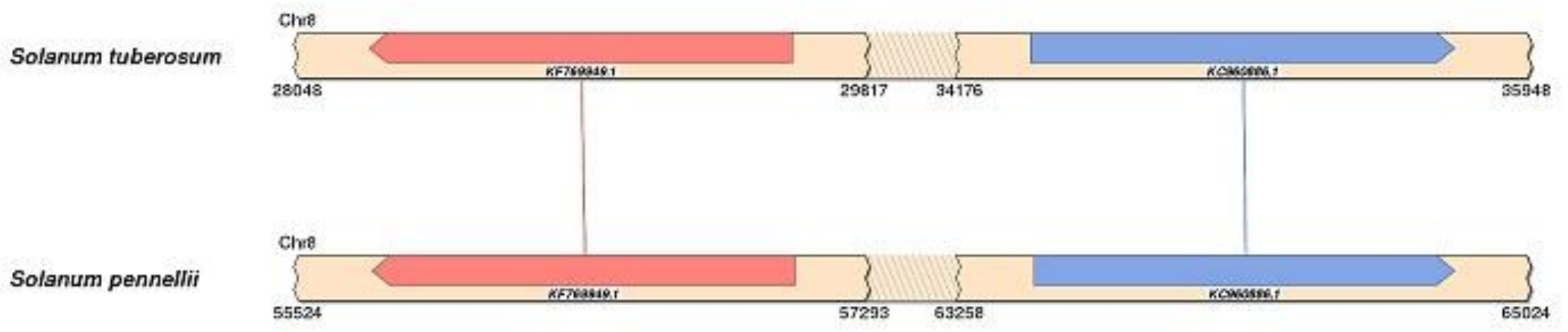


xo

$\times 1$

$\mathrm{x} 11$

$x 0$

$\times 1$

$\times 10$

$x 0$

$\times 1$

$\times 10$

$\mathrm{x} 11$

xo

$x 1$

$\times 10$

$\times 11$

xo

$\times 1$

$\times 10$

$\mathrm{x} 11$

$x 0$

$\mathrm{x} 1$

$\times 10$

$\mathrm{x} 11$

xo

$\times 1$

$\times 10$

$x 0$

$\times 1$

$\times 10$

$\times 11$

QNQTSFRPKGLIIPVTKDASTLQYLTQIQQRTPLVPISLTLDLGGQFLWVDCDQGYVSSS QNQ_-EVLYIPVTKDASTLEYI IEVGQRTPLIPIKLLINLGGRSLWVDCDKGYKSST --QTNFHPKTFFLAVKQDPSTLQYITEIQQRTPLVPVKLAVHVGGENLWVDCKTGFKSST

YKPARCRSAQCSLGGASGCGECFSPP--RPGCNNNTCGLLPDNTVTRTA--TSGELASDI YKPAVCNSTQCTFAKSHACGDCIFKPQVQPGCSNNTCYIWGENPLIN-SFHDRAEIAEDV YKPARCESAQCELAWSTSCGNCYVNNTLLPICNS--CYNVVSNPVTS----TGGEIAEDV YKPARCNSRQCTLARSTSCGDCKTKNKTRPGCNNNACYNIVSNPALNNTFYSGAEIAEDV

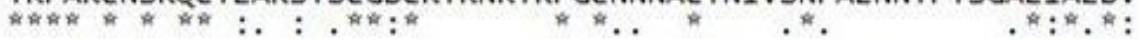

VSVQSTNGK----NPGRSVSDKNFLFVCG-ATFLLQGLASGVKGMAGLGR-TRISLPSQ LAIGS---TPGVRVTWPRFIFSCLLDQDMMRQFANGVTGVAGFGRESPVSIPNQ LTIQSINGS----IPGPVAIVPNFIFSCPITSNLTQNL GKNVKGMVGFGQQSPVSFATQ LTIQSINGSNTGPESRGPVVTIPKFIFSCS-PSFLTQKLGEDVKGMIGFGQQSPVSFVTQ

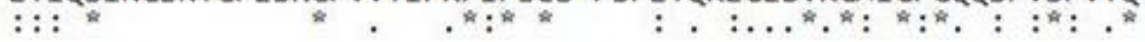

FSAEFSFPRKFALCLTSS-NSKGVVLFGDGPYFFLPNREF-SNNDFQYTPLFINPVSTAS LALDSRFTKKFGICLSSSTQSRGVIFIGSGPYYVYNPKKIDISNDILYTKLIANTRGGFV FASIFKFSRQFASCLSSSTKRNGVIFIGHSPYFI--SLAFDASRDLIYTPIITQQRFITI LASAFKFSRQFAICLSSSPQENGIIFIGHRPYLF--AFGFDASQDLFYTPII------$:::^{*}$. ${ }^{*}::^{*}: 0^{*}:::^{*}{ }^{*} . \quad: .^{*}:{ }^{*}::$

AFSSG----QPSSEYFIGVKSIKINQKVVPINTTLLSID-NQGVGGTKISTVNPYTILET T---1---SEEYIQVSSIRIAGQDVPLNKTLLSINKKNGVAGTRISTATPFTILHT TYPHYVRIIRPSPEYYIQVTSIRINGKTLPLNKTLLSLD-ENEEGGTRISTDVPYTELEP -

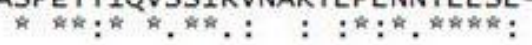
$* *, * * * x^{*} * *$

SLYNAITNFFVKELA-NVTRV-AAVAPFKVCFDSRNIGST--RVGPAVPSIDLVLONENV TIYDAFKTAFIKALPKNVTIVEPPMKQFGLCFSSKNIKST--NVGPDVPVIDFVLHKPSA SIYDIVSKAFITEMPKEVKKV-PAVQPFKTCFDSTYIGVS--RLGYDAPEINLVFQKQNV SIYRAVSKAFISEMPKNVKTV-SPVAPFKTCFNSSF IGISPLRLGYNAPGIYFVLHNPNV

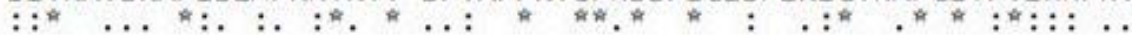

VWTIFGANSMVQVSENVLCLGVLDGGVNSRTSIVIGGHTIEDNLLQFDHAASRLGFTSSI FWRIYGTNSVVQVNKDVMCLAFVGRDQTWEPSIVIGGHQMEENLLVFDLVRRNIGFSSSL YWTIIGSNSL VKVKEGVICLAFVERKKSTGQAIVVGGYQMQDNLIEFDLSRSRIGFSNSL FWTITGANSLLLVNQGVFCLAFVEGKKETGEAIVIGSYQMQNNLVEFDLARRRIGFTNSL

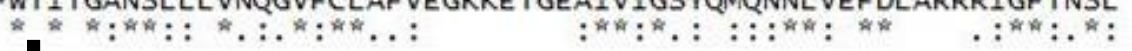

LFRQTTCANFNFTSIA

KLQQASCSKYDNTILG

FYHQTMCANHNYA-IN

FFROTMCSDPFTSIN

$$
\text { " : }{ }^{*}: \text { : }: \text { : I }
$$

https://mc.manuscriptcentral.com/cjps-pubs 


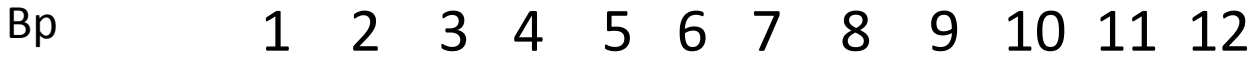

1000

500 
Table 1. Assessment of foliar inoculation with Phytophthora infestans ( race US 11) at 6 days.

\begin{tabular}{|c|c|c|}
\hline Transformant & Lesion size $(\mathrm{cm})$ & Sporulation (0-4 scale) \\
\hline Kennebec control & 3.0 & 3.0 \\
\hline Bintje control & 3.0 & 4.0 \\
\hline Kennebec X11-1 & 4.0 & 1.0 \\
\hline Kennebec X11-2 & 3.0 & 2.0 \\
\hline Kennebec X11-3 & 3.5 & 2.0 \\
\hline Kennebec X11-4 & 3.5 & 2.0 \\
\hline Kennebec X11-5 & 3.5 & 4.0 \\
\hline Kennebec X11-6 & 3.75 & 3.0 \\
\hline Kennebec X11-7 & 3.0 & 2.5 \\
\hline Kennebec X11-8 & 3.25 & 2.5 \\
\hline BintjeX11-1 & 3.5 & 4.0 \\
\hline BintjeX11-2 & 3.0 & 3.5 \\
\hline BintjeX11-3 & 3.5 & 3.5 \\
\hline BintjeX11-4 & 3.75 & 3.5 \\
\hline BintjeX11-5 & 3.25 & 2.5 \\
\hline BintjeX11-6 & 3.5 & 4.0 \\
\hline BintjeX11-7 & 3.25 & 4.0 \\
\hline BintjeX11-8 & 3.5 & 4.0 \\
\hline BintjeX11-9 & 2.75 & 2.0 \\
\hline Kennebec X10-1 & 2.75 & 2.5 \\
\hline BintjeX10-1 & 1.25 & 1.0 \\
\hline BintjeX10-2 & 1.25 & 0.5 \\
\hline BintjeX10-3 & 1.0 & 0.5 \\
\hline
\end{tabular}


